\title{
PELAKSANAAN KESELAMATAN DAN KESEHATAN KERJA TERHADAP PEKERJA HARIAN LEPAS PADA PHENON EVENT DENPASAR
}

\author{
Geraldine Thirdaswari Adnyana, Fakultas Hukum Universitas Udayana, e- \\ mail: geraldinetaaaa@gmail.com \\ I Wayan Wiryawan, Fakultas Hukum Universitas Udayana, e-mail: \\ wayan_wiryawan@yahoo.com
}

doi: https://doi.org/10.24843/KS.2020.v08.i11.p14

\begin{abstract}
ABSTRAK
Penulisan jurnal ini bertujuan untuk mengetahui pelaksanaan keselamatan dan kesehatan kerja bagi pekerja harian lepas serta untuk mengetahui faktor-faktor yang menjadi hambatan dalam pelaksanaan perlindungan hukum atas kesehatan dan keselamatan kerja bagi pekerja harian lepas pada Perusahaan Phenon Event di Denpasar. Metode penelitian yang digunakan yakni metode penelitian hukum empiris, menggunakan pendekatan dari peraturan perundang-undangan (the statue approach) dan pendekatan fakta. Hasil penelitian menunjukkan bahwa Perusahaan Phenon Event Denpasar belum melaksanakan kesehatan dan keselamatan kerja sesuai dengan standar yang diatur dalam Peraturan Menteri Kesehatan No. 48 Tahun 2016 Tentang Standar Keselamatan dan Kesehatan Kerja Perkantoran. Adapun faktorfaktor yang menjadi hambatan dalam pelaksanaan perlindungan kesehatan dan keselamatan kerja pada Perusahaan Phenon Event Denpasar adalah ketidakmampuan perusahaan untuk memenuhi standar kesehatan dan keselamatan kerja sebagaimana diatur dalam Peraturan Menteri Kesehatan No. 48 Tahun 2016 Tentang Standar Keselamatan dan Kesehatan Kerja Perkantoran.
\end{abstract}

Kata kunci : Pelaksanaan, Kesehatan dan Keselamatan Kerja, Pekerja Harian Lepas.

\begin{abstract}
This journal writing aims to determine the implementation of occupational safety and health for casual daily workers and to find out the factors that become obstacles in the implementation of legal protection for occupational health and safety for casual daily workers at the Phenon Event Company in Denpasar. The research method used is the empirical legal research method, using the approach of statutory regulations (the statue approach) and the fact approach. The results showed that the Phenon Event Denpasar Company had not implemented occupational health and safety in accordance with the standards stipulated in the Minister of Health Regulation No. 48 of 2016 concerning Office Work Safety and Health Standards. The factors that become obstacles in the implementation of occupational health and safety protection at the Phenon Event Denpasar Company are the company's inability to meet occupational health and safety standards as regulated in the Minister of Health Regulation No. 48 of 2016 concerning Office Work Safety and Health Standards.
\end{abstract}

Keywords: Implementation, Occupational Health and Safety, Daily Workers.

\section{Pendahuluan}

\subsection{Latar Belakang}

Selaku umat manusia memiliki wewenang untuk mencukupi kebutuhan kehidupan dengan cara bekerja. Memperoleh pekerjaaan serta pencaharian yang layak untuk kemanusiaan bahwasannya merupakan hak dari tiap warga negara yang 
merupakan kebutuhan mendasar bagi warga negara. ${ }^{1}$ Dalam Undang-Undang Dasar Republik Indonesia 1945 menyebutkan bahwa semua manusia memiliki hak dalam pengembangan diri dengan cara memenuhi keperluan sandang, pangan dan papan. Disamping itu manusia pun punya hak dalam pemenuhan pendidikan serta manfaat ilmu pengetahuan dan teknologi, kesenian dan budaya dalam meningkatkan kualitas hidupnya dan demi kesejahteraan manusia dalam pasal $28 \mathrm{C}$ bab XA. Pembukaan Undang-Undang Dasar Republik Indonesia 1945 terdapat tujuan dari bernegara (staatside) yaitu "memajukan kesejahteraan umum untuk mewujudkan keadilan sosial bagi seluruh rakyat Indonesia", hal ini diharap menjadi landasan dogma dan mandate untuk semua warga Indonesia dalam mewujudkannya. Oleh sebab itu sudah sepatutnya para pekerja untuk mendapatkan pemeliharaan, pembangunan, perlindungan dan kesejahteraan. ${ }^{2}$

Pekerjaan dapat dilakukan dengan beragam baik itu bekerja sendiri atau bekerja pada orang lain. Hal ini menyampaikan bahwa seorang ahli hukum mengatakan bentuk usaha tergolong ke dalam dua jenis, ${ }^{3}$ yaitu bekerja pada badan swasta milik perorangan atau badah hukum milik pemerintah. Hal tersebut dapat dinyatakan dalam dunia usaha yang rata-rata sangat digemari oleh kebanyakan para pelaku usaha bisnis berbadan hukum adalah Perseroan Terbatas. ${ }^{4}$ Dalam menjalankan sebuah perusahaan, pelaku usaha membutuhkan pekerja untuk dapat membantu mengoperasionalkan perusahaannya agar mendapatkan keuntungan. ${ }^{5}$

Perlindungan kerja sudah tercantum di Undang-Undang Ketenagakerjaan yang meliputi perlindungan teknis, ekonomis dan sosial. Hubungan kerja yang aturannya mengenai pekerja dan pengusaha dasarnya memuat hak dan kewajiban dari para pihak. 'Salah satu hak pekerja yang dilindungi adalah perjanjian kerja, karena perjanjian kerja adalah landasan terbentuknya hubungan kerja dan perjanjian tersebut dapat sah jika telah mencukupi persyaratan keabsahan perjanjian dan asas hukum perikatan. ${ }^{7}$ Dalam pembuatan sebuah perjanjian kerja dibutuhkan peranan asas-asas hukum dalam mewujud kan tujuan dari perjanjian itu sendiri. ${ }^{8}$ Perjanjian kerja berdasarkan waktu terbagi atas dua yakni perjanjian kerja waktu tertentu (PKWT) dan

1 Made Ayu Ratih Sanjiwani Giri, 2019, Pelaksanaan Upah Minimum Regional (UMR) Bagi Pekerja Alih Daya Pada PT. Delta Duta Dewata di PT. PLN (PERSERO) Distribusi Bali, Udayana University Press, Denpasar. Hlm. 3

2 I Gusti Ngurah Agung Niki Diatmika, I Made Sarjana dan I Made Dedy Priyanto, "Pelaksanaan Jaminan Sosial Bidang Kecelakaan Bagu Pekerja Outsourcing Pada PT Prima Karya Sarana Sejahtera di Denpasar", Kertha Semaya: Journal Ilmu Hukum (2015), hlm. 3

3 Suryadi, Asep, "Tanggung Jawab Direksi dalam Kepailitan Perseroan Terbatas" Jurnal Wawasan Yuridika 26,No.1 (2014):471-485

4 Dharmawan, Ni Ketut Supasti. "Keberadaan Pemegang Saham dalam Rups Dengan Sistem Teleconference Terkait Jaringan Bermasalah dalam Perspektif Cyber Law." Jurnal Magister Hukum Udayana4,No.1(2015):44188

5 Prabandari, P.R.(2014) "Kedudukan Hukum Perusahaan Bentuk Usaha Tetap (Permanent Establishment) Dalam Dimensi Hukum Penanaman Modal di Indonesia". Jurnal Magister Hukum Udayana (Udayana Master Law Journal),3(3),hlm. 440

6 Suhartoyo, "Perlindungan Hukum Bagi Buruh Dalam Sistem Hukum Ketenagakerjaan Nasional", Administrative Law \& Governance Journal, Universitas Diponegoro2,No.2(2019),hlm.328

7 Wijayanti, Asri. Hukum ketenagakerjaan pasca reformasi. Vol. 1. Sinar Grafika, 2009.

8 Sinaga, Niru Anita, "Peranan Asas-Asas Hukum Dalam Perjanjian", Jurnal Binamulia Hukum, Fakultas Hukum Universitas Dirgantara Marsekal Suryadarma7,(2008),109. 
perjanjian kerja waktu tidak tertentu (PKWTT). ${ }^{9}$ PKWT atau yang biasa disebut dengan pekerja harian lepas definisinya berpatokan dengan lamanya jangka waktu atau berakhirnya pekerjaan tesebut. Perjanjian kerja waktu tertentu memberikan fundamen hukum dan tersusun pada Keputusan Menteri Tenaga Kerja dan Transmigrasi Republik Indonesia Nomor:KEP.100/MEN/VI/2004 tentang Ketentuan Pelaksanaan Perjanjian Kerja Waktu Tertentu (seterusnya disingkat KEP.100/MEN/VI/2004). Undang-Undang Ketenagakerjaan mendefinisikan hubungan kerja sebagai relasi yang terjadi antara pelaku usaha dengan para pekerja berdasar perjanjian kerja, perjanjian kerja tersebut dapat berupa unsur-unsur yang terdiri dari upah, pekerjaan yang dapat dikerjakan, dan perintah dimana semua pekerja yang bekerja baik itu untuk negara maupun untuk perusahaan swasta telah memiliki perlindungan hukum dimana hak dan kewajibannya telah diatur oleh Undang-Undang Ketenagakerjaan. Perjanjian kerja tidak memuat persyaratan yang telah tercantum pada UU tidak bisa dinyatakan depan hukum, walaupun beberapa pihak dinyatakan ikut terlibat, konsekuensinya adalah hakim akan membubarkan atau menyatakan bahwa perjanjian tersebut batal.

Setiap orang yang mempunyai pekerjaan dimanapun mereka berprofesi, baik bagi negara atau bagi perusahaan swasta mendapatkan perlindungan hukum dimana hak dan kewajibannya sudah disusun oleh Undang-Undang Ketenagakerjaan. Tenaga kerja memiliki perbedaan definisi dengan pekerja, "tenaga kerja adalah setiap orang yang mampu melakukan pekerjaan guna menghasilkan barang dana tau jasa baik untuk memenuhi kebutuhan sendiri maupun untuk masyarakat". ${ }^{10}$ Namun memiliki bentuk perlindungan hukum yang sama dengan perlindungan yang diberikan pada hukum ketenagakerjaan yakni perlindungan hukum bagi pekerjanya yang didalamnya diatur tentang jangka waktu perlindungan yang diberikan. ${ }^{11}$ Tujuan dari dibentuknya perlindungan tenaga ini adalah untuk menjamin keberlangsungan dari sistem hubungan kerja secara harmonis antara pelaku usaha dan tenaga kerjanya tanpa disertai adanya tekanan dari pihak yang kuat kepada pihak yang lemah.

Adapun artikel yang terkait dengan penulisan ini berjudul "Perlindungan Hukum Terhadap Keselamatan dan Kesehatan Pekerja Pada PT Tea Kirana"yang beralamat di Jl. Sari Gading No. 81 Denpasar, perusahaan ini bergerak di bidang jasa konstruksi bangunan. ${ }^{12}$ Penulisan tersebut mengangkat permasalahan tentang pelaksanaan perlindungan hukum keselamadan dan kesehatan pekerja pada PT Tea Kirana serta faktor-faktor yang menjadi penghambat dalam pelaksanaannya. Artikel serupa juga ditemukan berjudul "Implementasi Undang-Undang No. 13 tahun 2003 Terhadap Kecelakaan Kerja di UD. Intan" yang bergerak di bidang pengolahan kayu untuk dijadikan furniture. ${ }^{13}$ Penulisan tersebut mengangkat permasalahan tentang

9 Amalia,Apei,dkk, “Analisis Yuridis Perjanjian Kerja Waktu Tertentu Berdasarkan UndangUndang Ketenagakerjaan dan Hukum Perjanjian", USU Law Jurnal 5,No.1 (2017), 69.

10 Subijanto, 2011, "Peran Negara dalam Hubungan Tenaga Kerja Indonesia" Jurnal Pendidikan dan Kebudayaan Vol. 17 No.6, hlm.708

11 Eka Prasetya Purnomo,2018, Implementasi Perlindungan Hukum Terhadap Kecelakaan Kerja Bagi Pekerja Mini Market (Studi Kasus: Indomaret Kebo Iwa Denpasar), Kertha Semaya: Journal Ilmu Hukum (2018), hlm.4

12 Ida Ayu Krisna Kartika Dewi, I Made Udiana, 2019, Perlindungan Hukum Terhadap Keselamatan dan Kesehatan Pekerja/ Buruh Pada PT. Tea Kirana Denpasar, Kertha Semaya: Journal Ilmu Hukum, hlm. 6

13 Komang Agus Wahyu Tricahyadinata, A.A. Ketut Sukranatha, 2020, "Implementasi UndangUndang No. 13 tahun 2003 Terhadap Kecelakaan Kerja di UD. Intan", Kertha Semaya: Journal Ilmu Hukum, hlm.4 
bentuk perlindungan hukum pekerja di UD Intan serta pertanggungjawaban UD Intan terhadap pekerja apabila terjadi kecelakaan kerja.

\subsection{Rumusan Masalah}

Sesuai dengan latar belakang persoalan yang telah dirangkum diatas, dapar diambil dua dalil permasalahan yang telah dirangkum, antara lain:

1. Bagaimanakah pelaksanaan perlindungan hukum atas kesehatan dan keselamatan kerja bagi pekerja harian lepas pada Perusahaan Phenon Event di Denpasar?

2. Faktor-faktor apa saja yang menjadi kendala dalam pelaksanaan perlingungan hukum atas kesehatan dan keselamatan kerja bagi pekerja harian lepas pada Perusahaan Phenon Event di Denpasar?

\subsection{Tujuan Penulisan}

Tujuan dari penulisan jurnal ini adalah untuk mengetahui pelaksanaan kesehatan dan keselamatan kerja terhadap pekerja harian lepas pada Perusahaan Phenon Event di Denpasar, serta mengetahui adanya faktor-faktor kendala baik itu dari dalam maupun dari luar perusahaan yang kiranya menghambat aturan Kesehatan dan Keselamatan Kerja.

\section{Metode Penelitian}

Metode penelitian yang digunakan dalam jurnal ini adalah metode penelitian hukum empiris. Penelitian hukum empiris merupakan penelitian yang dilakukan dengan cara observasi atau penelitian dengan cara langsung terjun ke lapangan guna untuk mendapatkan kebenaran yang akurat ${ }^{14}$, dimana metode ini dapat dihubungkan dengan meneliti perusahaan yang sudah atau belum melaksanakan aturan-aturan Kesehatan dan Keselamatan Kerja. Metode penelitian ini menggunakan pendekatan untuk mengkaji permasalahan yakni pendekatan perundang-undangan (The Statue Approach) dan pendekatan fakta kasus (Case Approach). Pendekatan perundangundangan dilakukan untuk menelaah aturan-aturan yang ada sangkut pautnya dengan permasalahan (isu hukum) yang sedang dihadapi. Sedangkan pendekatan fakta kasus dilakukan untuk menelaah kasus-kasus yang berkaitan dengan isu hukum yang sedang dihadapi. Sumber data pada penelitian ini bersumber dari data primer yang berasal dari penelitian lapangan (field research) yaitu berupa wawancara (interview)dari beberapa pokok pertanyaan yang telah dipersiapkan sebelumnya. Data Sekunder yang terdiri dari Bahan Hukum Primer dengan menelaah peraturanperundang-undangan yang terkait dengan permasalahan yang dikaji. Bahan hukum sekunder merupakan bahan hukum yang erat hubungannya dengan bahan hukum primer. Bahan hukum sekunder didapat dari penelitian kepustakaan (library research) seperti buku-buku, peraturan perundang-undangan, peraturan menteri dan peraturan pemerintah. Bahan hukum tersier adalah pelengkap sumber bahan hukum primer dan sekunder, seperti Kamus Besar Bahasa Indonesia (KBBI), kamus hukum, Wikipedia dan Ensiklopedia. Teknik analisis menggunakan materi-materi yang sudah berhasil dikumpulkan, kemudian dilakukan pengolahan dan analisis data secara sistematis berupa uraian pokok-pokok yang berkualitas secara jelas, teratur, logis dan terperinci. Materi-materi tersebut disajikan secara deskriptif analis.

14 Diantha, I. Made Pasek, and MS SH. Metodologi penelitian hukum normatif dalam justifikasi teori hukum. Prenada Media, 2016. 


\section{Hasil dan Pembahasan}

3.1. Pelaksanaan Perlindungan Hukum Atas Kesehatan dan Keselamatan Kerja Bagi Pekerja Harian Lepas Pada Perusahaan Phenon Event di Denpasar

Definisi pekerja harian lepas menurut Peraturan Menteri Tenaga Kerja Nomor PER-06/MEN/1985 tentang Perlindungan Pekerja Harian Lepas adalah seseorang yang memiliki pekerjaan dan bekerja dibawah pimpinan pelaku usaha guna mencapai visi misi dari perusahaan tersebut serta bisa berubah dalam baik itu waktu dan kapasitas pekerjaan dengan mendapat upah berdasar upah harian. Semua pekerja yang bekerja disamping punya kewajiban, juga harus punya hak dan kesempatan setara tanpa terjadi diskriminasi antar maupun dalam negri. ${ }^{15}$ Hak dan kewajiban tersebut meliputi pelatihan kerja yang dilangsungkan oleh perusahaaan (pasal 9 PER/06/MEN/1985), memperoleh rancangan yang diciptakan PERUM ASTEK (pasal 8), mendapat upah harian sesuai ketentuan (pasal 7), pekerja melakukan pekerjaan berhubungan dengan produk baru yang masih dalam masa eksperimen maksimal kurun waktu 2 tahun perpanjang 1 tahun (pasal 8 KEP.100/MEN/VI/2004), pekerja harian lepas merakit perjanjian kerja scara tertulis dengan pelaku usaha yang tercantum sekurang-kurangnya nama, alamat, jenis pekerjaan, besar upah (pasal 12 KEP.100/MEN/VI/2004).

Menurut Menteri Tenaga Kesehatan, kesehatan dan keselamatan kerja adalah cara yang dilakukan untuk menangggulangi serta mencegah penimbulan kecelakaan yang mungkin saja terjadi dan penanggulangan bahaya dengan cara mengimplementasikan penanggulangan bahaya dengan tepat dan menyelenggarakan aturan undang-undangan tentang Keesehatan dan Keselamatan Kerja. Sumber bahaya muncul kedalam lingkungan kerja tergolong atas 5 kategori, yaitu:

1) Bangunan yang dilengkapi dengan konstruksi dan instalasi yang bersifat mumpuni.

2) Bahan-bahan yang bersifat membahayakan, seperti: mudah terbakar, mudah meledak, menimbulkan kerusakan pada jaringan tubuh, mengakibatkan kanker,beracun, radioaktif.

3) Proses, yang asalnya dari beragam jenis sesuai dengan teknologi yang digunakan

4) Langkah kerja, yang dapat menyebabkan cidera pada karyawan seperti mengangkut barang berat, hembusan debu dan serbuk logam, recikan api dan tumpahan bahankimia dan bahaan lain yang berresiko tinggi.

5) Lingkungan kerja, penyebab permasalahan kesehatan serta penyakit yang menyerang seseorang saat bekerja di area perkantorannya dan penurunan infentifitas dan kemampuan bekerja.

Para pekerja dalam perusahaan ini telah menjalankan sedikit dari aturan Kesehatan dan Keselamatan Kerja yang salah satunya adalah menerapkan program cerminan hidup bersih dengan cara mencuci tangan dengan sabun sebelum berkegiatan, sebelum dan setelah makan. ${ }^{16}$ Selain pola hidup bersih yang diterapkan,

15 Vijayantera, I. Wayan Agus. "Pengaturan Tunjangan Hari Raya Keagamaan Sebagai Hak Pekerja Setelah Diterbitkan Peraturan Menteri Tenaga Kerja Nomor 6 Tahun 2016." Jurnal Ilmiah Fakultas Hukum Universitas Udayana 47 (2016): 143.

16 Berdasarkan wawancara yang dilakukan di dalam Perusahaan Phenon Event dengan Christyn Meirina selaku Manager of Human Resource pada Perusahaan Phenon Event di Denpasar, tanggal 23 juni 2020. 
ada juga pola hidup sehat yatu menjaga kesehatan fisik dengan cara berolah raga. Aktifitas fisik yang dilaksanakan adalah kegiatan Muai Thai yang berlangsung hari rabu sore. Muay Thai merupakan seni bela diri keras dari Kerajaan Thailand yang telah terbentuk selama dua ribu tahun. ${ }^{17}$ Penghindaran penyakit di area kantor berupa eliminasi yaitu dengan memberikan multivitamin dan suplemen kepada semua pekerja. Disamping itu, barang substitusi yang disediakan berupa makanan gandum dan mie instan.

Beberapa peralatan lainnya yang terdapat dalam perusahaan tersebut berupa alat pelindung diri, yakni: sabuk pengaman (safety belt), sepatu boot karet, sarung tangan (hand gloves), masker mulut, tali pengaman (safety harness), kacamata pengaman (safety glasses), helm, power tools. Beberapa peralatan yang telah dijabarkan ini digunakan di lapangan dalam acara / event. Peralatan tersebut merupakan peralatan yang digunakan untuk menyusun dekorasi panggung, sound system dan fasilitasfasilitas portable lainnya.

Pekerja harian lepas dibutuhkan pada saat-saat tertentu, semisal pada saat perusahaan sedang mengadakan event. Pekerjaan yang dibutuhkan dapat berupa ticketing division, sales promotor, usher, doorman, runners (membantu perlengkapan production division), dan pecalang. Para pekerja seperti ini kadang kurang diperhatikan dalam hal Kesehatan dan Keselamatan Kerja karena perusahaan berfikir bahwa para pekerjanya hanya sementara dan perusahaan merasa rugi apabila memberikan fasilitas tersebut kepada pekerja yang tidak memberikan keuntungan banyak kepada perusahaannya sendiri. Perlindungan bagi para pekerja dilakukan dengan memberi arahan serta menambah pengakuan atas hak asais manusia, perlindungan teknis, fisik, maupun sosial ekonomi dengan cara mempraktekkan norma yang berlaku di lingkungan kerja. perlindungan teknis lainnya yang terdapat pada kantor yaitu Alat Pemadam Api Ringan (APAR) sesuai dengan Peraturan Menteri Pekerja dan Transmigrasi No. 04/MEN/1980 tentang Syarat-syarat Pemasangan dan Pemeliharaan Alat Pemadam Api Ringan.

\subsection{Faktor-Faktor yang Menjadi Kendala dalam Pelaksanaan Perlindungan Hukum Atas Kesehatan dan Keselamatan Kerja Bagi Pekerja Harian Lepas Pada Perusahaan Phenon Event di Denpasar}

Beberapa kendala yang dapat digolongkan kedalam beberapa bagian yaitu intern dan ekstern. Faktor intern merupakan faktor terjadi di dalam perusahaan. Berdasarkan Peraturan Menteri Kesehatan Republik Indonesia No. 48 Tahun 2016 tentang Standar Kesehatan Kerja Perkantoran terdapat persyaratan kesehatan kerja pasal 15 adalah:

1) Peningkatan kesehatan kerja, yaitu peningkatan tentang kesehatan kerja, perilaku hidup bersih dan sehat, penyediaan ruang ASI, olahraga.

2) Pencegahan penyakit, contohnya pengendalian faktor risiko meliputi eliminasi, substitusi, pengendalian teknis/rekayasa, pengendalian administratif dan APD, penemuan dini kasus penyakit.

3) Penanganan penularan penyakit di perkantoran

4) Pemulihan kesehatan bagi karyawan

17 Wikipedia, URL: https://id.wikipedia.org/wiki/Muay_Thai ,diakses tanggal 11 Agustus 2020 
Standar Keselamatan Kerja tercantum pada pasal 12 Peraturan Menteri Kesehatan Republik Indonesia No. 48 tahun 2016 tentang Standar Kesehatan Kerja Perkantoran, yaitu:

1) Persyaratan keselamatan kerja perkantoran, meliputi perawatan ruang kantor dan alat-alat perkantoran serta listrik dan sumber api

2) Kewaspadaan bencana perkantoran yang dimaksut adalah gedung darurat, jalur evakuasi, penggunaan mekanik dan elektrik, P3K

Salah satu yang merupakan penanggung jawab dari aturan ketenagakerjaan adalah Direksi, karena merupakan seseorang yang ditunjuk untuk menjadi pemimpin sebuah perusahaan tempat ia bekerja selama masa jabatannya. Para anggota direksi sewajibnya memiliki itikad baik dalam melaksanakan jabatannya demi kepentingan perusahaan. ${ }^{18}$ Ibu Christyn Meirina mengatakan adanya hambatan yang sedang terjadi di masyarakat dalam menghadapi kegiatan dari program Kesehatan dan Keselamatan Kerja adalah perusahaan kurang memahami dan mengetahui pengetahuan mengenai program Kesehatan dan Keselamatan Kerja, yang tentunya para pekerja kurang fasih dalam peristiwa ini karena mereka rasa perusahaan kurang menghiraukan program Kesehatan dan Keselamatan Kerja.

Faktor ekstern merupakan faktor yang terjadi dari luar perusahaan. Adapun faktor ekstern yang dapat menghambat pelaksanaan aturan pemerintah Kesehatan dan Keselamatan Kerja pada perusahaan tersebut adalah kurangnya pengawasan yang dilakukan oleh Dinas Tenaga Kerja dan Energi Sumber Daya Mineral Provinsi Bali. Dinas Tenaga Kerja tersebut diberikan kewenangan untuk membantu Gubernur melaksanakan urusan pemerintah di bidang Tenaga Kerja dan bidang Energi Sumber Daya Mineral yang menjadi kewenangan daerah, serta melaksanakan tugas dekonsentrasi, yang dipimpin oleh seorang Kepala Dinas, yang berada di bawah dan bertanggung jawab kepada Gubernur melalui Sekretaris Daerah. Pengawasan dilaksanakan oleh dinas terkait penerapan Kesehatan dan Keselamatan Kerja pada setiap perusahaan walaupun Kesehatan dan Keselamatan Kerja merupakan aturan yang sah dimata hukum dan peraturannya telah tercantum di berbagai peraturan perundang-undangan. Pemerintah juga jarang melaksanakan penyuluhan yang berkaitan dengan penerapan standar Kesehatan dan Keselamatan Kerja yang dapat berupa penerapan program-program yang dibuat pemerintah. Menurut pendapat Ibu Gung Jaya mengatakan bahwa ${ }^{19}$ tidak sedikit perusahaan yang tidak memprioritaskan program Kesehatan dan Keselamatan Kerja dalam standar pengoperasional di perusahaannya, karena perusahaan lebih mementingkan kinerja para pekerja dalam beroperasi tanpa memikirkan efek jangka panjang yang akan timbul dari melalaikan program Kesehatan dan Keselamatan Kerja. Salah satu alasan perusahaan tidak mempraktekkan peraturan Kesehatan dan Kesselamatan Kerja dalam perusahaannya adalah perusahaan tidak bisa menjamin dengan adanya aturan K3 berupa Jaminan Keselamatan Kerja (JKK) dan Jaminan Kematian (JKM) akan menjadikan kinerja pekerja akan lebih bagus lagi, karena peraturan perusahaan yang seadanya dirasa sudah sangat cukup untuk dilakukan.

18 Suharto, Eduard Rudy. "PERTANGGUNGJAWABAN DIREKTUR ATAS KEWENANGAN MEWAKILI PERSEROAN TERBATAS YANG TELAH HABIS MASA KEPENGURUSANNYA." JURNAL RECHTENS8, No.1(2019).

19 Berdasarkan wawancara yang dilakukan di dinas Tenaga Kerja dan Energi Sumber Daya Mineral Provinsi Bali dengan Ibu A.A. Jaya Ningsih selaku Sekretaris Kepala Sub. Bag., tanggal 3 juni 2020. 


\section{Kesimpulan}

Kesehatan dan Keselamatan Kerja pada Perusahaan Phenon Event di Denpasar dirasa masih kurang berjalan seutuhya. Beberapa jenis aturan Kesehatan dan Keselamatan Kerja menurut Peraturan Menteri Kesehatan No. 48 Tahun 2016 tentang Standar Keselamatan dan Kesehatan Kerja Perkantoran masih belum terlaksana semua didalam Perusahaan tersebut seperti penyediaan ruangan untuk Ibu Menyusui. Standar kesehatan lingkungan kerja seperti pencegahan dan penanganan penyakit menular di perkantoran serta pemulihan kesehatan karyawannya masih belum terlaksana. Adapun standar kesehatan dan keselamatan kerja yang sudah dilaksanakan oleh Perusahaan Phenon Event adalah sarana bangunan, penyediaan air, toilet, cuci tangan pakai sabun, pengamanan pangan, alat pemadam api dan alat pelindung diri (APD). Adapun faktor-faktor yang menjadi hambatan dalam pelaksanaan perlindungan kesehatan dan keselamatan kerja pada Perusahaan Phenon Event di Denpasar adalah ketidakmampuan perusahaan untuk memenuhi standar kesehatan dan keselamatan kerja sebagaimana diatur dalam Peraturan Menteri Kesehatan No. 48 Tahun 2016 Tentang Standar Keselamatan dan Kesehatan Kerja Perkantoran.

\section{DAFTAR PUSTAKA}

\section{Buku:}

Wijayanti, Asri. Hukum ketenagakerjaan pasca reformasi. Vol. 1. Sinar Grafika, 2009.

Diantha, I. Made Pasek, and MS SH. Metodologi penelitian hukum normatif dalam justifikasi teori hukum. Prenada Media, 2016.

Marzuki, Peter Mahmud. Penelitian hukum. Kencana, 2005.

\section{Jurnal:}

Giri, Made Ayu Ratih Sanjiwani, and I. Wayan Wiryawan. "Pelaksanaan Upah Minimum Regional (Umr) Bagi Pekerja Alih Daya Pada PT. Delta Duta Dewata Di PT. Pln (Persero) Distribusi Bali." Kertha Semaya: Journal Ilmu Hukum 7, no. 2 (2019): 1-15.

Diatmika, I. Gusti Ngurah Agung Niki, I. Made Sarjana, and I. Made Dedy Priyanto. "Pelaksanaan Jaminan Sosial Bidang Kecelakaan Bagi Pekerja Outsourcing Pada PT Prima Karya Sarana Sejahtera Di Denpasar." Kertha Semaya 3, no. 03 (2015).

Suryadi, Asep, "Tanggung Jawab Direksi dalam Kepailitan Perseroan Terbatas" Jurnal Wawasan Yuridika 26,No.1 (2014):471-485

Dharmawan, Ni Ketut Supasti. "Keberadaan Pemegang Saham dalam Rups Dengan Sistem Teleconference Terkait Jaringan Bermasalah dalam Perspektif Cyber Law." Jurnal Magister Hukum Udayana4,No.1(2015):44188

Prabandari, Putu Ratih. "Kedudukan Hukum Perusahaan Bentuk Usaha Tetap (Permanent Establishment) Dalam Dimensi Hukum Penanaman Modal Di Indonesia." Jurnal Magister Hukum Udayana 3, no. 3 (2014): 44129.

Suhartoyo, Suhartoyo. "Perlindungan Hukum Bagi Buruh Dalam Sistem Hukum Ketenagakerjaan Nasional." Administrative Law \& Governance Journal 2, no. 2 (2019): 326-336.

Sinaga, Niru Anita. "Peranan Asas-Asas Hukum Perjanjian Dalam Mewujudkan Tujuan Perjanjian." Binamulia Hukum 7, no. 2 (2018): 107-120. 
Amalia, Apri, Budiman Ginting, Agusmidah Agusmidah, and Yefrizawati Yefrizawati. "Analisis Yuridis Perjanjian Kerja Waktu Tertentu Berdasarkan Undang-undang Ketenagakerjaan dan Hukum Perjanjian." USU Law Journal 5, no. 1 (2017): 164960.

Subijanto, Subijanto. "Peran Negara dalam Hubungan Tenaga Kerja di Indonesia." Jurnal Pendidikan Dan Kebudayaan 17, no. 6 (2011): 705-718.

Purnomo, Eka Prasetya, I. Ketut Markeling, and I. Nyoman Darmadha. "Implementasi Perlindungan Hukum Terhadap Kecelakaan Kerja Bagi Pekerja Mini Market (Studi Kasus: Indomaret Kebo Iwa Denpasar)." Kertha Semaya: Journal Ilmu Hukum (2018): 1-13.

Permana, Sang Made Satya Dita, I. Wayan Wiryawan, and I. Ketut Westra. "Kedudukan Hukum Direksi Terhadap Pengelolaan Perseroan Terbatas Yang Belum Berstatus Badan Hukum." Kertha Semaya: Journal Ilmu Hukum 5, no. 2 (2017).

Hariyanto, Erie. "BURGELIJK WETBOEK (Menelusuri Sejarah Hukum Pemberlakuannya Di Indonesia)." Al-Ihkam: Jurnal Hukum Dan Pranata Sosial 4, no. 1 (2013): 140-152.

Vijayantera, I. Wayan Agus. "Pengaturan Tunjangan Hari Raya Keagamaan Sebagai Hak Pekerja Setelah Diterbitkan Peraturan Menteri Tenaga Kerja Nomor 6 Tahun 2016." Jurnal Ilmiah Fakultas Hukum Universitas Udayana 47 (2016): 143.

Suharto, Eduard Rudy. "PERTANGGUNGJAWABAN DIREKTUR ATAS KEWENANGAN MEWqAKILI PERSEROAN TERBATAS YANG TELAH HABIS MASA KEPENGURUSANNYA." JURNAL RECHTENS 8, no. 1 (2019).

Dewi, Ida Ayu Krisna Kartika, I. Made Udiana, MH SH, and I. Ketut Markeling. "PERLINDUNGAN HUKUM TERHADAP KESELAMATAN DAN KESEHATAN PEKERJA/BURUH PADA PT. TEA KIRANA DENPASAR."

Tricahyadinata, Komang Agus Wahyu, and AA Ketut Sukranatha. "IMPLEMENTASI UNDANG-UNDANG NOMOR 13 TAHUN 2003 TERHADAP KECELAKAAN KERJA DI UD. INTAN." Kertha Semaya: Journal Ilmu Hukum 8, no. 3: 368-381.

\section{Peraturan perundang-undangan}

Undang-Undang Dasar Negara Republik Indonesia Tahun 1945

Undang-Undang Republik Indonesia Nomor 13 Tahun 2003 Tentang Ketenagakerjaan

Keputusan Menteri Tenaga Kerja dan Transmigrasi Republik Indonesia Nomor : KEP.100/MEN/VI/2004 Tentang Ketentuan Pelaksanaan Perjanjian Kerja Waktu Tertentu

Peraturan Menteri Tenaga Kerja Nomor PER-06/MEN/1985 Tentang Perlindungan Pekerja Harian Lepas

Peraturan Menteri Tenaga Kerja dan Transmigrasi Nomor : PER.04/MEN/1980 Tentang Syarat-syarat Pemasangan dan Pemeliharaan Alat Pemadam Api Ringan

Peraturan Menteri Kesehatan Republik Indonesia Nomor 48 Tahun 2016 Tentang Standar Keselamatan dan Kesehatan Kerja Perkantoran

\section{Internet}

Wikipedia, URL: https://id.wikipedia.org/wiki/Muay_Thai ,diakses tanggal 11 Agustus 2020 